\title{
Modern contraception use and associated factors in Ethiopia: Evidence from the 2019 Ethiopian Mini Demographic and Health Survey
}

Girum Taye Zeleke ( $\nabla$ girumt2000@yahoo.com )

Ethiopian Public Health Institute

Theodros Getachew Zemedu

Ethiopian Public Health Institute

\section{Research Article}

Keywords: Modern Contraceptives, Ethiopia, mini-DHS

Posted Date: February 17th, 2022

DOI: https://doi.org/10.21203/rs.3.rs-1334697/v1

License: (c) (1) This work is licensed under a Creative Commons Attribution 4.0 International License.

Read Full License 


\section{Abstract}

Background: The use of contraceptive is key in reducing unsafe abortion from unintended pregnancies, infant mortality, adolescent pregnancies, slowing population growth and helps to prevent HIV/AIDS. However, less than one-third of women within reproductive age in Ethiopia uses modern contraceptive methods. Hence, this study aims to identify potential factors on use of modern contraceptive method.

Methods: Data from 2019 Ethiopian min Demographic and Health Survey were used in this analysis. A total of 8,885 women within the ages of 15-49 years across 305 enumeration areas in nine regions and two city administrations were included in the analysis. Logistic regression model used to examine the association between women's background characteristics and modern contraceptives use.

Results: Only $28.1 \%$ of women used modern contraceptives. About $40 \%$ of the modern contraceptive users were between age of 25-29 and 30-34 years. There was significant association between women's age, level of education, region, religion, parity, wealth quintile and marital status on use of modern contraceptives. Women who were married and living with partners were about 20 and 24 times more likely to use modern contraceptives compared to sexually active unmarried women.

Conclusion: The study showed that the use of modern contraceptive method is low and influenced by socio-demographic characteristics of women in Ethiopia. Therefore, increasing the awareness of women to use modern contraceptive methods is vital.

\section{Background}

The world's population by 2015 was estimated at 7.3 billion and projected to be 8.5 billion in 2030 (1). This world population projection increment mainly depends on high total fertility rate of countries including Ethiopia in which it had a total fertility rate of 4.6 children per woman in 2016 (2). The population of Ethiopia was estimated in 2007 at about 73 million and it is projected to be about 127 million by 2037 (3).

The use of contraceptive is key in reducing unsafe abortion and unintended pregnancies (4) . However, the recent Ethiopian Mini Demographic and Health Survey have shown a low uptake of contraceptive methods and high-unmet needs. The survey reported about $29 \%$ contraceptive prevalence rate among all women between ages 15 to 49 years with only $28 \%$ users of modern contraceptive methods (5).

Previous studies in Ethiopia, Nigeria, Malawi and Ghana have shown evidence of the influence of age, parity, educational level, socioeconomic status, fertility intention, cultural belief, and awareness of Family Planning (FP) methods, fear of side effects, partner's disapproval, misconceptions and myths on low uptake of modern contraceptive methods (6-10).

Therefore, this study aimed to examine how the use of modern contraceptive method is influenced by socio-demographic characteristics of women in Ethiopia. 


\section{Methods}

\section{Study setting}

Data from 2019 Ethiopian min Demographic and Health Survey were used in this analysis.

The sample for the survey was stratified and selected in two stages.

In the first stage, 305 enumeration areas (EAs) from a frame of all EAs created for the 2019 Ethiopia Population and Housing Census by Central Statistical Agency selected with probability proportional to EAs size.

In the second stage, a fixed number of 30 households per EAs selected with an equal probability systematic selection from the newly created household listing. All women age 15-49 who were either permanent residents of the selected households or visitors who slept in the household the night before the survey were eligible for interview.

\section{Study variables}

The dependent variable is use of modern contraceptive methods during the survey, categorized as 'Yes' for those who uses PILL, IUD, injectable, implants, male condom, emergency contraception, standard days method (SDM), lactational amenorrhoea (LAM) and other users, while "No" for those who uses rhythm, withdrawal, other, and none users of family planning methods.

Individual-level variables include respondent age, residence, region, education and wealth quintile.

\section{Data analysis}

To summarize initially the study variables alone and to explore association between study variables with utilization of modern contraceptive methods; univariate descriptive and bivariate analysis implemented, respectively. For these analyses, survey-weighting variable used. To examine the crude association between use of modern contraceptive methods and study variables, univariate binary logistic regression model applied. To examine the overall adjusted association, variables indicated association at $5 \%$ level of significance in bivariate analysis were included in a multivariate logistic regression. Finally, measure of associations of the study variables on use of modern contraceptive methods examined using adjusted Odds Ratio (OR) at 95\% confidence interval (Cl). All the analyses done using SPSS Version 20.

\section{Results}

Table 1 presents background characteristics of women who were included in the survey.

From the total 8,885 women in the survey, those in age group 15-19 years were the highest proportion (24.9\%) followed by women in age group 25-29 (18.8\%). Most of women in the survey were completed primary level of education (41.7\%) while $5.7 \%$ of the women have more than secondary educational level. 
Generally, compared to their respective categories more proportion of women in this survey were from rural areas (67.8\%) and Oromia regional state (37.7\%); Orthodox religion (41.5\%); married (64.6\%); with zero parity (32.8\%) and in the highest wealth quintile (25.7\%).

Modern contraceptives were used by $28.1 \%$ of women, of which $18.7 \%$ were injectable, $6 \%$ implants, $1.4 \%$ pill, $1 \%$ IUD, $0.4 \%$ LAM, $0.3 \%$ female sterilization and $0.2 \%$ male condom and $0.1 \%$ SDM.

As shown in Table 2, modern contraceptives were $2.1 \%$ among single women, $2.2 \%$ widow, $12.7 \%$ separated $14.6 \%$ divorced, $40.4 \%$ married and $43 \%$ living with their partners.

About $40 \%$ of the modern contraceptive users were between ages of $25-29$ and $30-34$ years followed by women in age group 20-24 (34.7\%). (Table 2).

The univariate binary logistic regression analysis showed a significant association $(p<0.001)$ of women's age group, educational level, region, religion, parity, wealth quintile and marital status. (Table 2). These variables were subsequently included in the multivariate logistic regression model.

The multivariate binary logistic regression in Table 3 showed that, women in age group 20-24 (aOR:1.66, 95\% C.I:1.31-2.11), 25-29 (aOR:1.54, 95\% C.I: 1.21 - 1.97), 30-34 (aOR:1.61, 95\% C.I: 1.22-2.11), 35-39 (aOR:1.34, 95\% C.I: 1.01-1.78) were more likely to use modern contraceptive while women in age group 45-49 (aOR:0.40, 95\% C.I:0.27-0.59) were less likely compared to those in age group 15-19 during the survey . Comparison by level of education shows, women with primary levels of education [aOR: 1.47, 95\% C.I: 1.27-1.7] and with secondary level of education [aOR: 1.29, 95\% C.I: 1.04-1.59] were more likely to use modern contraceptive compared to those who had no education.

Regarding modern contraceptive use in different regions, women in Afar (aOR:0.60, 95\% C.I:0.41-0.86) and Somali (aOR:0.16, 95\% C.I: 0.09 - 0.29) were less likely to use modern contraceptive compared to those women in Tigray region, while those women in Amhara (aOR:1.82, 95\% C.I: 1.42-2.33), Oromia (aOR:1.62, 95\% C.I: 1.24-2.12), Benishangul-Gumuz (aOR:1.57, 95\% C.I: 1.19-2.06) and SNNPR (aOR:1.84, 95\% C.I: 1.39-2.43) were more likely to use modern contraceptive compared to those women in Tigray region.

Regarding wealth quintile, women in the highest wealth quintile [aOR: 2.91, 95\% C.I: 2.33-3.63], fourth [aOR: 2.15, 95\% C.I: 1.74-2.65], middle [aOR: 1.94, 95\% C.I: 1.57-2.39], second [aOR: 1.65, 95\% C.I: 1.342.04] were more likely to use modern contraceptive compared to those in the lowest wealth quintile.

\section{Discussion}

About a quarter of women in reproductive age who were included in the study used modern contraceptive. This study also identified women's age, educational level, region, religion, parity, wealth quintal and marital status to be significant factors that were influencing modern contraceptive use. 
This study used national and regional representative data to reflect the prevalence of the reproductive age women modern contraceptive utilization and its possible associated factors. The data were collected through adapted DHS program's standard questionnaires.

Since Mini-DHS is a cross-sectional type of survey, temporal relationship between contraceptive use and associated factors cannot be assured and the evidence should be used in caution.

Findings in 2019 Ethiopian Mini Demographic and Health survey shows that uptake of weighted modern contraceptive method at national level has improved to $28.1 \%$ from previous years Ethiopian Demographic and Health Survey, that is $9.7 \%$ in 2005, 18.7\% in 2011 and $24.9 \%$ in $2016(2,5,11,12)$.

Although improvements have been shown, the contraceptive acceptance rate in Ethiopia by 2020 was $69 \%$ while its HSTP target for this year was $85 \%$ (13).

The utilization of modern contraceptive cannot be generalized to the general population. It only represents the study population. However, a large number of women were included in this study so that the association made could be considered as a robust.

Our study shows that place of residence that is living in urban or rural was not a significant factor influencing modern contraceptive use among women in reproductive age. This was in contrast with findings from other studies in Ghana and Democratic Republic Congo $(14,15)$.

The likelihood of modern contraceptive use was higher among married and living with partner women compared to those who are unmarried but sexually active. Possible explanations for this might be good husband's/partner support on contraceptive use (16) or women's independency in making beneficial reproductive health decisions (17).

Findings from a multi-country study conducted by health policy initiative in 2007 across 47 developing countries revealed the inequalities in the use of family planning observed among different women groups(18).

Our study findings also indicated similar patterns with these studies; that is women from highest wealth quintal, primary level of education, SNNPR/Amhara regions and 1 to 2 parity being more likely to use modern contraceptive compared to women in lowest wealth quintal, with no education, from Tigray and with no parity, respectively.

It implies to improve the gap of up taking modern contraceptive, the policy makers who are working in the area need to give more attention for reproductive age women from lowest quintile, for Afar and Somali regions and with no education.

Focusing on married women, result of 2019 Ethiopia mini-DHS showed that the contraceptive prevalence rate equals $41.4 \%$ that is still below HSTP-II target of $50 \%$ planned for $2024 / 25$. In order to achieve this 
target in the remaining 2 years, interventions like health education on advantage of contraceptive use, community mobilization and improvement in family planning accessibility are among the key strategies.

\section{Conclusion}

Modern contraceptive utilization in Ethiopian women in the reproductive age is found to be low. This study also pointed out a disparity in modern contraceptive use among regions, and wealth quintiles. In addition, we found low utilization of modern contraceptive among unmarried women, 15-19 age group, and Muslim women. Women's age, educational level, region, religion, parity, wealth quintal and marital status associated with modern contraceptive use.

\section{Abbreviations}

aOR: adjusted Odds Ratio;

Cl: Confidence Interval;

CSA: Central Statistical Agency;

DHS: Demographic and Health Survey;

EPHI: Ethiopian Public Health Institute;

FP: Family Planning;

HSTP; Health Sector Transformation Plan;

IRB: Institutional Review Board;

LAM: Lactational Amenorrhoea;

MoH: Ministry of Health;

SDM: Standard Days Method;

SPSS: Statistical Package for Social Science;

SNNPR: Southern Nations and Nationalities Peoples Region

\section{Declarations}

\section{Ethics approval and consent to participate}

This study used existing Ethiopian Mini DHS 2019 survey secondary data with all identifying information removed. For this, after our application MEASURE DHS granted to access the data. DHS Program ICF 
Research Ethics Committee and Ethiopian Public Health Institute Review Board approved the survey. Prior to the actual interview, each woman ages 15-49 asked if she agreed to participate in the survey and individual written consent obtained. During the primary survey data collection, all ethical principles and methods carried out in accordance with Ethiopian national research ethics guideline.

\section{Consent for publication}

Not Applicable.

\section{Availability of data and materials}

Data are available in a public, open access repository. The data for this study were sourced from Demographic and Health Survey and are available at http://www.dhsprogram.com/data/availabledatasets.cfm.

\section{Competing interests}

The authors declare that they have no financial and non-financial competing interests.

\section{Funding}

Not applicable.

\section{Authors' contributions}

GZ contributed to design the manuscript concept, data analysis, and manuscript drafting. TZ played a vital role in data analysis and critical revision of the manuscript. Both authors read and approved the manuscript.

\section{Acknowledgments}

Our first appreciation goes to DHS program for providing us 2019 mini EDHS data. We would also like to extend our deepest gratitude to EPHI, CSA, MoH and other stakeholders for their successful implementation of the survey. Finally, we thank all study participants, program coordinators, fieldwork supervisors and data collectors.

\section{References}

1. United Nations D of E and SAPD. Population 2030: Demographic challenges and opportunities for sustainable development planning. 2015.

2. Central Statistical Agency (CSA) [Ethiopia] and ICF. Ethiopia Demographic and Health Survey 2016. Addis Ababa, Ethiopia, and Rockville, Maryland, USA: CSA and ICF . 2016

3. Central Statistica Agency (CSA) [Ethiopia]. Population Projections for Ethiopia 2007-2037. 2013. 
4. Kwame KA, Bain LE, Manu E, Tarkang EE. Use and awareness of emergency contraceptives among women of reproductive age in sub-Saharan Africa: a scoping review. BMC Contraception and Reproductive Medicine. 2022;7(1):1-14.

5. Ethiopian Public Health Institute (EPHI) [Ethiopia] and ICF. Ethiopia Mini Demographic and Health Survey 2019: Final Report. Rockville, Maryland, USA: EPHI and ICF. 2021.

6. Latifat Ibisomi. Is age difference between partners associated with contraceptive use among married couples in Nigeria?. International Perspective on Sexual and Reproductive Health. 2014;40(1):39-45.

7. Stephen A Adebowale, Sunday A Adedini, Latifat D Ibisomi, Martin E Palamuleni. Differential effect of wealth quintile on modern contraceptive use and fertility: Evidence from Malawian women. BMC Womens Health. 2014;14(1).

8. Chinelo C. Okigbo, llene S. Speizer, Marisa E. Domino,Sian L.Curtis. A Multilevel Logit Estimation of Factors Associated With Modern Contraception in Urban Nigeria. World Med Health Policy. 2017;9(1):6588.

9. Yihunie Lakew, Ayalu A Reda , Habtamu Tamene, Susan Benedict, Kebede Deribe. Geographical variation and factors influencing modern contraceptive use among married women in Ethiopia: Evidence from a national population based survey.BioMed Central Reproductive Health. 2013;10(52):2-10.

10. Michelle J Hindin, Laura J McGough, Richard M Adanu. Misperceptions, misinformation and myths about modern contraceptive use in Ghana. BMJ Sexual \& Reproductive. 2014;40(1):30-35.

11. Central Statistical Agency (CSA) [Ethiopia] and ICF. Ethiopia Demographic and Health Survey 2005. Addis Ababa, Ethiopia, and Rockville, Maryland, USA: CSA and ICF . 2005

12. Central Statistical Agency (CSA) [Ethiopia] and ICF. Ethiopia Demographic and Health Survey 2011. Addis Ababa, Ethiopia, and Rockville, Maryland, USA: CSA and ICF . 2011.

13. Ministry of Health [Ethiopia]. Health Sector Transformation Plan I Health and Health Related Indicators. 2020.

14. Philomina Akadity Aviisah, Samuel Dery, Benedicta Kafui Atsu, Alfred Yawson, Refah M. Alotaibi. Modern contraceptive use among women of reproductive age in Ghana: Analysis of the 2003-2014 Ghana Demographic and Health Surveys. BMC Women's Health. 2018;18(1):1-10.

15. Mbdu Fidele Muanda, Gahungo Parfait Ndongo, Lauren J. Messina, Jane T. Bertrand. Barriers to modern contraceptive use in rural areas in DRC. Culture, Health and Sexuality. 2017;19(9):1011-1023, DOI: 10.1080/13691058.2017.1286690.

16. Ndola Prata, Suzanne Bell, Ashley Fraser, Adelaide Carvalho, Isilde Neves, Benjamin Nieto-Andrade. Partner support for family planning and modern contraceptive use in Luanda, Angola. African Journal of 
Reproductive Health. 2017;21(2):35-48.

17. Afework Tadele, Amanuel Tesfay, Alemi Kebede. Factors influencing decision-making power regarding reproductive health and rights among married women in Mettu rural district, south-west, Ethiopia. BMC Reproductive Health. 2019;16(1):1-9.

18. USAID. Inequalities in the Use of Family Planning and Reproductive Health Services: Implications for Policies and Programs. Health Policy Initiative. 2007.

\section{Tables}

Table1. Distribution of Women by background characteristics 


\begin{tabular}{|c|c|c|}
\hline Variables & Frequency & Weighted Percentage \\
\hline \multicolumn{3}{|l|}{ Age group } \\
\hline $15-19$ & 2100 & 24.9 \\
\hline $20-24$ & 1578 & 16.7 \\
\hline $25-29$ & 1752 & 18.8 \\
\hline $30-34$ & 1166 & 13.1 \\
\hline $35-39$ & 1037 & 12.0 \\
\hline $40-44$ & 714 & 8.3 \\
\hline $45-49$ & 538 & 6.3 \\
\hline \multicolumn{3}{|l|}{ Educational level } \\
\hline No education & 3640 & 40.4 \\
\hline Primary & 3345 & 41.7 \\
\hline Secondary & 1149 & 12.2 \\
\hline More than Secondary & 751 & 5.7 \\
\hline \multicolumn{3}{|l|}{ Residence } \\
\hline Urban & 2951 & 32.2 \\
\hline Rural & 5934 & 67.8 \\
\hline \multicolumn{3}{|l|}{ Region } \\
\hline Tigray & 733 & 7.1 \\
\hline Afar & 641 & 1.0 \\
\hline Amhara & 948 & 22.8 \\
\hline Oromia & 1052 & 37.7 \\
\hline Somali & 640 & 4.7 \\
\hline Benishangul-Gumuz & 747 & 1.1 \\
\hline SNNPR & 1008 & 19.2 \\
\hline Gambela & 723 & 0.5 \\
\hline Harari & 763 & 0.3 \\
\hline Addis Ababa & 818 & 5.0 \\
\hline Dire Dawa & 812 & 0.7 \\
\hline
\end{tabular}




\begin{tabular}{|c|c|c|}
\hline Orthodox & 3374 & 41.5 \\
\hline Catholic & 78 & 0.5 \\
\hline Protestant & 1711 & 27.4 \\
\hline Muslim & 3635 & 29.5 \\
\hline Traditional & 60 & 0.9 \\
\hline Other & 27 & 0.2 \\
\hline \multicolumn{3}{|l|}{ Marital status } \\
\hline Single & 2300 & 26.2 \\
\hline Married & 5613 & 64.6 \\
\hline Living with partner & 129 & 1.4 \\
\hline Widowed & 227 & 2.1 \\
\hline Divorced & 424 & 4.2 \\
\hline Separated & 192 & 1.5 \\
\hline \multicolumn{3}{|l|}{ Parity } \\
\hline None & 2897 & 32.8 \\
\hline 1 to 2 & 2404 & 25.2 \\
\hline 3 to 4 & 1705 & 19.1 \\
\hline 5 and above & 1879 & 22.9 \\
\hline \multicolumn{3}{|l|}{ Wealth quintile } \\
\hline Lowest & 2031 & 16.2 \\
\hline Second & 1341 & 18.2 \\
\hline Middle & 1268 & 18.8 \\
\hline Fourth & 1344 & 21.1 \\
\hline Highest & 2901 & 25.7 \\
\hline Total & 8885 & 100 \\
\hline
\end{tabular}

Table2. Distribution and association between utilization of modern contraceptive on study variables 


\begin{tabular}{|c|c|c|}
\hline Variables & $\begin{array}{l}\text { Use of modern FP } \\
\text { n (weighted \%) }\end{array}$ & $\begin{array}{l}\text { Traditional or non FP users } \\
\text { n (weighted \%) }\end{array}$ \\
\hline \multicolumn{3}{|l|}{ Age group } \\
\hline $15-19$ & $164(9.4)$ & $1936(90.6)$ \\
\hline $20-24$ & $435(34.7)$ & $1143(65.3)$ \\
\hline $25-29$ & $568(40.5)$ & $1184(59.5)$ \\
\hline $30-34$ & $380(39.5)$ & $786(60.5)$ \\
\hline $35-39$ & $305(34.1)$ & $732(65.9)$ \\
\hline $40-44$ & $150(26.9)$ & $564(73.1)$ \\
\hline $45-49$ & $59(13.7)$ & $479(86.3)$ \\
\hline \multicolumn{3}{|l|}{ Educational level } \\
\hline No education & $759(27.6)$ & $2881(72.4)$ \\
\hline Primary & $841(28.6)$ & $2504(71.4)$ \\
\hline Secondary & $267(26.3)$ & $882(73.7)$ \\
\hline More than Secondary & $194(31.0)$ & $557(69.0)$ \\
\hline \multicolumn{3}{|l|}{ Residence } \\
\hline Urban & $697(29.4)$ & $2254(70.6)$ \\
\hline Rural & $1364(27.4)$ & $4570(72.6)$ \\
\hline \multicolumn{3}{|l|}{ Region } \\
\hline Tigray & $183(26.2)$ & $550(73.8)$ \\
\hline Afar & $63(11.6)$ & $578(88.4)$ \\
\hline Amhara & $319(34.4)$ & $629(65.6)$ \\
\hline Oromia & $288(27.5)$ & $764(72.5)$ \\
\hline Somali & $15(2.9)$ & $625(97.1)$ \\
\hline Benishangul-Gumuz & $202(26.3)$ & $545(73.7)$ \\
\hline SNNPR & $313(31.1)$ & $695(68.9)$ \\
\hline Gambela & $176(22.5)$ & $547(77.5)$ \\
\hline Harari & $152(18.5)$ & $611(81.5)$ \\
\hline Addis Ababa & $205(24.7)$ & $613(75.3)$ \\
\hline
\end{tabular}




\begin{tabular}{|c|c|c|}
\hline Dire Dawa & $145(18.5)$ & $667(81.5)$ \\
\hline \multicolumn{3}{|l|}{ Religion } \\
\hline Orthodox & $998(31.7)$ & $2376(68.3)$ \\
\hline Catholic & $20(44.7)$ & $58(55.3)$ \\
\hline Protestant & $465(31.3)$ & $1246(68.7)$ \\
\hline Muslim & $562(20.1)$ & $3073(79.9)$ \\
\hline Traditional & $9(20.5)$ & $51(79.5)$ \\
\hline Other & $7(25.7)$ & $20(73.3)$ \\
\hline \multicolumn{3}{|l|}{ Marital status } \\
\hline Single & $2245(2.1)$ & $55(97.9)$ \\
\hline Married & $3737(40.4)$ & $1876(59.6)$ \\
\hline Living with partner & $78(43.0)$ & $51(57.0)$ \\
\hline Widowed & $221(2.2)$ & $6(97.8)$ \\
\hline Divorced & $376(14.6)$ & $48(85.4)$ \\
\hline Separated & $167(12.7)$ & 25 (87.3) \\
\hline \multicolumn{3}{|l|}{ Parity } \\
\hline None & $225(8.3)$ & $2672(91.7)$ \\
\hline 1 to 2 & $891(45.5)$ & $1513(54.5)$ \\
\hline 3 to 4 & $534(38.4)$ & $1171(61.6)$ \\
\hline 5 and above & $411(28.7)$ & $1468(71.3)$ \\
\hline \multicolumn{3}{|l|}{ Wealth quintile } \\
\hline Lowest & $231(20.2)$ & $1800(79.8)$ \\
\hline Second & $326(25.7)$ & $1015(74.3)$ \\
\hline Middle & $368(31.7)$ & $900(68.3)$ \\
\hline Fourth & $384(28.8)$ & $960(71.2)$ \\
\hline Highest & $752(31.5)$ & $2149(68.5)$ \\
\hline Total & $2061(28.1 \%)$ & $6824(71.9 \%)$ \\
\hline
\end{tabular}

Table 3. Effect of study variables on use of modern contraceptives using binary logistic regression 


\begin{tabular}{|c|c|c|c|c|}
\hline \multirow[t]{2}{*}{ Variables } & \multicolumn{2}{|c|}{ Unadjusted estimates } & \multicolumn{2}{|c|}{ Adjusted estimates } \\
\hline & Odds Ratio & 95\% C.I & Odds Ratio & 95\% C.I \\
\hline \multicolumn{5}{|l|}{ Age group } \\
\hline $15-19$ & 1 & & 1 & \\
\hline $20-24$ & 4.49 & $3.70-5.45$ & 1.66 & $1.31-2.11$ \\
\hline $25-29$ & 5.66 & $4.69-6.84$ & 1.54 & $1.21-1.97$ \\
\hline $30-34$ & 5.71 & $4.67-6.98$ & 1.61 & $1.22-2.11$ \\
\hline $35-39$ & 4.92 & $3.99-6.06$ & 1.34 & $1.01-1.78$ \\
\hline $40-44$ & 3.14 & $2.47-3.99$ & 0.92 & $0.67-1.26$ \\
\hline $45-49$ & 1.45 & $1.06-1.99$ & 0.40 & $0.27-0.59$ \\
\hline \multicolumn{5}{|l|}{ Educational level } \\
\hline No education & 1 & & 1 & \\
\hline Primary & 1.28 & $1.14-1.43$ & 1.47 & $1.27-1.70$ \\
\hline Secondary & 1.15 & $0.98-1.35$ & 1.29 & $1.04-1.59$ \\
\hline More than Secondary & 1.32 & $1.10-1.59$ & 1.28 & $0.99-1.64$ \\
\hline \multicolumn{5}{|l|}{ Residence } \\
\hline Urban & 1 & & & \\
\hline Rural & 0.97 & $0.87-1.07$ & - & - \\
\hline \multicolumn{5}{|l|}{ Region } \\
\hline Tigray & 1 & & 1 & \\
\hline Afar & 0.33 & $0.24-0.45$ & 0.60 & $0.41-0.86$ \\
\hline Amhara & 1.52 & $1.23-1.89$ & 1.82 & $1.42-2.33$ \\
\hline Oromia & 1.13 & $0.91-1.41$ & 1.62 & $1.24-2.12$ \\
\hline Somali & 0.07 & $0.04-0.12$ & 0.16 & $0.09-0.29$ \\
\hline Benishangul-Gumuz & 1.11 & $0.88-1.41$ & 1.57 & $1.19-2.06$ \\
\hline SNNPR & 1.35 & $1.09-1.68$ & 1.84 & $1.39-2.43$ \\
\hline Gambela & 0.97 & $0.76-1.23$ & 1.13 & $0.84-1.51$ \\
\hline Harari & 0.75 & $0.59-0.95$ & 0.77 & $0.57-1.04$ \\
\hline Addis Ababa & 1.01 & $0.80-1.27$ & 1.01 & $0.75-1.35$ \\
\hline Dire Dawa & 0.65 & $0.51-0.84$ & 0.80 & $0.59-1.09$ \\
\hline
\end{tabular}




\section{Religion}

Orthodox

1

1

Catholic

0.82

$0.49-1.37$

1.16

$0.62-2.15$

Protestant

0.89

$0.78-1.01$

0.71

$0.59-0.85$

Muslim

0.44

$0.39-0.49$

0.54

$0.46-0.64$

Traditional

0.42

$0.21-0.86$

0.40

$0.19-0.86$

Other

0.83

$0.35-1.98$

0.85

$0.32-2.28$

\section{Parity}

None

1

1

1 to 2

6.99

$5.96-8.20$

1.64

$1.31-2.04$

3 to 4

5.42

$4.57-6.42$

1.44

$1.12-1.86$

5 and above

3.33

$2.79-3.96$

1.25

$0.95-1.66$

\section{Wealth quintile}

Lowest

Second

Middle

Fourth

Highest

\section{Marital status}

Single

Married

Living with partner

Widowed

Divorced

Separated
1

2.50

3.19

3.12

2.73

1

20.49

26.69

1.11

5.21

6.11
1

$2.08-3.01 \quad 1.65$

$1.34-2.04$

$2.65-3.83$

1.94

$1.57-2.39$

$2.60-3.74$

2.15

$1.74-2.65$

$2.32-3.20$

2.91

$2.33-3.63$ 